\title{
Characteristics of the Reanalysis and Satellite-Based Surface Net Radiation Data in the Arctic
}

\author{
Minji Seo ${ }^{(D)}{ }^{1}$ Hyun-Cheol Kim $(\mathbb{D})^{2}$ Kyeong-Sang Lee ${ }^{(D)}{ }^{1}$ Noh-Hun Seong ${ }^{1}{ }^{1}$ \\ Eunkyung Lee $\mathbb{D},{ }^{3}$ Jinsoo Kim $\mathbb{D}^{1},{ }^{1}$ and Kyung-Soo Han $\mathbb{D}^{1}$ \\ ${ }^{1}$ Division of Earth Environmental System Science (Major of Spatial Information Engineering), Pukyong National University, \\ Busan 48513, Republic of Korea \\ ${ }^{2}$ Unit of Arctic Sea-Ice Prediction, Korea Polar Research Institute, Incheon 21990, Republic of Korea \\ ${ }^{3}$ Korea Ocean Satellite Center, Korea Institute of Ocean Science \& Technology, Busan 49111, Republic of Korea
}

Correspondence should be addressed to Kyung-Soo Han; kyung-soo.han@pknu.ac.kr

Received 25 June 2020; Revised 18 August 2020; Accepted 28 August 2020; Published 17 September 2020

Academic Editor: Lei Zhang

Copyright $\odot 2020$ Minji Seo et al. This is an open access article distributed under the Creative Commons Attribution License, which permits unrestricted use, distribution, and reproduction in any medium, provided the original work is properly cited.

In this study, we compared four net radiation products: the fifth generation of European Centre for Medium-Range Weather Forecasts atmospheric reanalysis of the global climate (ERA5), National Centers for Environmental Prediction (NCEP), Clouds and the Earth's Radiant Energy System Energy Balanced and Filled (EBAF), and Global Energy and Water Exchanges (GEWEX), based on ground observation data and intercomparison data. ERA5 showed the highest accuracy, followed by EBAF, GEWEX, and NCEP. When analyzing the validation grid, ERA5 showed the most similar data distribution to ground observation data. Different characteristics were observed between the reanalysis data and satellite data. In the case of satellitebased data, the net radiation value tended to increase at high latitudes. Compared with the reanalysis data, Greenland and the central Arctic appeared to be overestimated. All data were highly correlated, with a difference of $6-21 \mathrm{~W} / \mathrm{m}^{2}$ among the products examined in this study. Error was attributed mainly to difficulties in predicting long-term climate change and having to combine net radiation data from several sources. This study highlights criteria that may be helpful in selecting data for future climate research models of this region.

\section{Introduction}

The Arctic has a complex climate system with atmosphereocean-land interactions and lower-latitude forcing that occur on various temporal and spatial scales [1]; thus, this area is particularly vulnerable to climate change $[2,3]$. The surface radiation budget (SRB) is a key parameter for understanding the polar regions, which have a high albedo and emissivity [4-7]. SRB can be used to characterize the net radiation, specifically, the balance between downward and upward shortwave solar radiation and longwave thermal radiation from the atmosphere and various surfaces [8]. It is effectively the remainder of the radiative energy on the Earth's surface. Surface net radiation plays an important role in not only the energy cycle but also the ecosystem and carbon and water cycles [8-11]. Remote sensing of the radiative flux can provide information on a global scale, as well as point-scale data from ground observations [12]. Due to these advantages, numerous radiative flux products have been derived from satellite and multispectral sensor data over the last decade [12]. Recently, various radiative flux products of the Arctic from satellite data and reanalysis data have been made available.

Satellite-based data, such as Clouds and the Earth's Radiant Energy System (CERES) [13], Global Energy and Water Exchanges Project (GEWEX) SRB [14], CloudSat [15], and Climate Monitoring Satellite Application Facility cLoud, Albedo and surface RAdiation dataset from Advanced Very High Resolution Radiometer (AVHRR) data-Edition 2 (CMSAF CLARA-A2) [16], provide information on radiative flux and radiative surface exchange processes. Reanalysisbased data, provided as absorbed solar radiation, includes 
the European Centre for Medium-Range Weather Forecasts (ECMWF) interim reanalysis (ERA-Interim) [17]; fifthgeneration ERA (ERA5) [18]; National Centers for Environmental Prediction/National Center for Atmospheric Research (NCEP/NCAR) [19]; Modern-Era Retrospective Analysis for Research and Applications, version 2 (MERRA-2) [20, 21]; and the Japan Meteorological Agency's Japanese 55-Year Reanalysis (JRA-55) [22].

Numerous studies have attempted to evaluate these radiation products; however, most were conducted at low to midlatitudes and only a few focused on the Arctic [23-29]. Riihelä et al. performed an intercomparison of radiative components on the Arctic during the spring and summer of 2007 [29]. Seo et al. compared CERES synoptic TOA and surface fluxes and clouds (SYN) and GEWEX SRB Arctic data from March 2003 to December 2007 [30]. Both of these studies analyzed only satellite data. Research has been conducted to develop the Arctic Observation and Reanalysis Integrated System (ArORIS) that combines satellite, reanalysis, and in situ products in the Arctic [28]. Studies evaluating the Arctic's net radiation have mostly been short term, on the order of 3 years or less, or are based on single-source data (satellitebased, reanalysis, or model data). Despite the many radiative products produced, comparative analysis by data type is lacking or has been carried out on accumulated data from the past. The analysis of recently updated data is still in progress.

In this study, we used data from the Arctic that has frequently been used in past research with recently updated radiation products. Among several reanalyzed data, ERA5 and NCEP data were used in this study. NCEP is a traditional reanalysis data developed in the 1990s, and the rest of the reanalysis data have been developed after the 2000s. ERA5 was selected because it is the most recently produced data and is calculated using various observation-based products as input data compared to past reanalysis data.

The purpose of this study was to assess the net radiation products over the Arctic using validation and intercomparison analyses. This paper is divided into two parts for validation and intercomparison analysis. The intercomparison analysis used four net radiation products: two reanalysis products, ERA5 and NCEP/NCAR, and two satellite-based products, CERES and GEWEX, for diversity. ERA5 and CERES Energy Balanced and Filled (EBAF) Edition 4.0 have been updated recently; NCEP/NCAR and GEWEX have been used for a longer period of time. This research is expected to provide some clarity regarding the accuracy of net radiation products and the relationship between product characteristics and comparative data from the Arctic for future modeling.

\section{Materials and Methods}

\subsection{Data}

2.1.1. ERA5. ERA5 is the fifth-generation ECMWF atmospheric reanalysis product of the global climate. ERA5 data are produced by Copernicus Climate Change Service (C3S) and provide the most recent atmospheric reanalysis of ECMWF. ERA5 is based on the new numerical weather product (IFS Cycle 41r2, 2016 version) [18]. Compared to ERA-Interim, ERA5 offers improved spatial resolution, from $79 \mathrm{~km}$ to $31 \mathrm{~km}$, and a higher output frequency, from every 6 hours (h) to hourly sampling from 1979 [31]. Therefore, ERA5 is a higher-resolution model, as a replacement for ERA-Interim [32, 33]. Atmospheric data assimilation has been upgraded to a 12 -hour 4D-Var ensemble, and advanced climate data are used for model input [33]. Observation data such as satellite data, weather station, buoy, and radiosonde have been used on an average of 0.75 million per day in 1979, when data assimilation begins, and 24 million in recent years.

C3S provides ERA5 products with a spatial resolution of $0.25^{\circ} \times 0.25^{\circ}$ in spherical coordinates. We used the monthly averaged EAR5 radiative flux data to match the temporal resolution provided by EBAF. Monthly average data refers to the entire month and is generated from all hourly data for the month. ERA5 is provided in joule per square meter, not in a common unit; it is necessary to convert the unit for comparing with other radiation products. In the case of monthly mean data, it is converted into watt per square meter by dividing 86400 seconds (24 hours).

2.1.2. NCEP. The NCEP/NCAR is a reanalysis product [19]. The spatial resolution of NCEP comprises a T62 Gaussian grid $\left(\sim 1.91^{\circ}\right)$, and temporal resolution is available at several levels, e.g., daily and monthly [34]. We selected monthly mean data to match the temporal resolution of EBAF data for the comparison. Radiative transfer schemes are based on the method of Lacis and Hansen [35] in the shortwave range and that of Schwarzkopf and Fels [36] in the longwave range [37].

2.1.3. EBAF. CERES EBAF is an all-sky surface flux product. Monthly data are presented as the monthly mean, with a spatial resolution of $1^{\circ}$ on a uniform grid. The EBAF data used in this study were acquired over the coverage period from March 2000 to March 2018, using the Surface Radiation Edition 4.0 data product (May 2017 release). The EBAF product is calculated using EBAF top-of-atmosphere (TOA) flux, temperature/humidity profiles based on CERES SYN1degMonth/SYN1deg-3hour, and cloud vertical profiles obtained from CALIPSO/CloudSat [38]. The EBAF product includes monthly surface upward/downward shortwave and longwave irradiances constrained by CERES-derived TOA irradiance [39]. CERES EBAF TOA Edition 4.0 was computed by Loeb et al. [40]. Kato et al. [39] determined the uncertainty in downward and upward shortwave irradiances of the North Pole to be 14 and $16 \mathrm{~W} / \mathrm{m}^{2}$, respectively, using this product; both downward and upward longwave irradiances were $12 \mathrm{~W} / \mathrm{m}^{2}$.

2.1.4. GEWEX. GEWEX SRB data provide several temporal resolutions of 1-hour, 3-hour, daily, and the monthly mean. We used monthly mean data to better coincide with the temporal resolution of EBAF for the comparison. The spatial resolution is $1^{\circ}$ for uniform grid data. The coverage period of the data was from July 1983 to December 2007. The satellitebased data are calculated from readings obtained from the 
TABLE 1: Summary of radiative flux products used in this study.

\begin{tabular}{lccccc}
\hline Dataset & Coverage & Temporal resolution & Spatial resolution & Based on & Version \\
\hline ERA5 & $1979.01-2019.03$ & Monthly mean & $0.25^{\circ} \times 0.25^{\circ}$ & Reanalysis & Monthly averaged reanalysis \\
NCEP & $1948.01-2018.12$ & Monthly mean & T62 Gaussian grid & Reanalysis & Mean monthly NMC reanalysis \\
GEWEX & $1983.07-2007.12$ & Monthly mean & $1^{\circ} \times 1^{\circ}$ & Satellite & LW: rel3.1 \\
EBAF & $2000.03-2018.03$ & Monthly mean & $1^{\circ} \times 1^{\circ}$ & Satellite & SW: rel3.0 \\
\hline
\end{tabular}

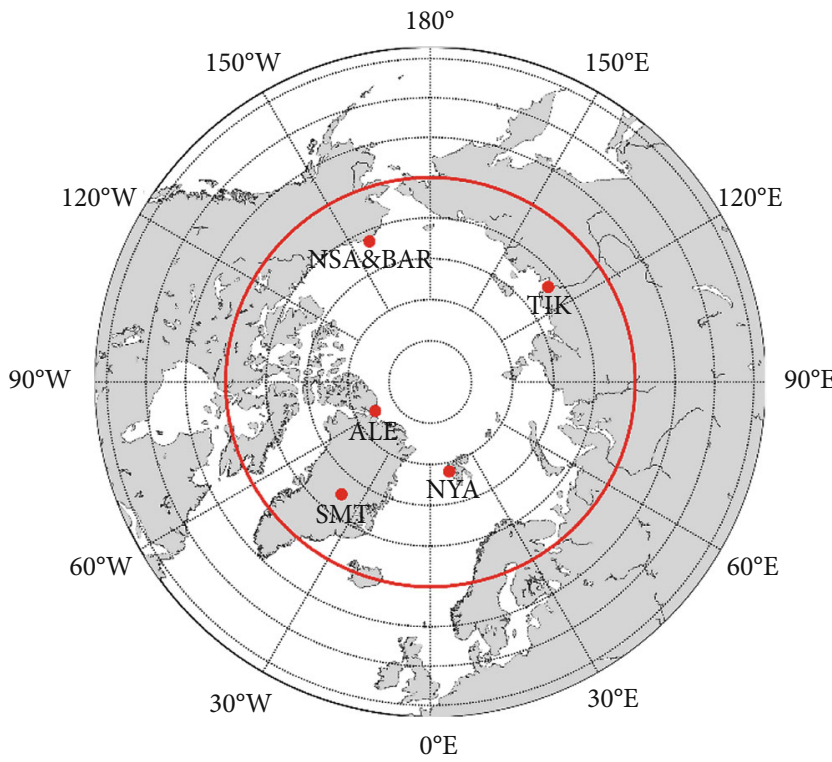

FIGURE 1: Locations of the six ground observation sites: Alert (ALE), Ny Alesund (NYA), Tiksi (TIK), Barrow (BAR), ETH/Greenland Summit (SMT), and North Slope of Alaska (NSA). The red circle indicates the Arctic Circle (poleward $65^{\circ} \mathrm{N}$ ).

AVHRR sensor mounted on the National Oceanic and Atmospheric Administration satellite [41]. Radiative transfer schemes use the Pinker and Laszlo [42] method in the shortwave range and that of $\mathrm{Fu}$ et al. [43] in the longwave range. Commonly used cloud information was obtained from the International Satellite Cloud Climatology Project [29]. GEWEX monthly mean data for shortwave irradiance shows a root mean square (RMS) accuracy of $23.34 \mathrm{~W} / \mathrm{m}^{2}$ and a bias of $-5.22 \mathrm{~W} / \mathrm{m}^{2}$. In the longwave range, the RMS accuracy was $11.1 \mathrm{~W} / \mathrm{m}^{2}$, with a bias of $0.9 \mathrm{~W} / \mathrm{m}^{2}$ from 1998 to 2007 [44, 45]. All accuracy values were calculated on a global scale.

Table 1 provides a summary of the spatial radiative flux data used in this study.

2.1.5. Ground Observation Data. Data from six ground observation sites monitored by three institutions were selected for this study, as discussed below. These data are used by the National Aeronautics and Space Administration for validation of CERES surface Edition 4.0 data and are provided by "EBAF Surface Ed4.0 Validation Subsetting and Browsing" and "CERES/ARM Validation Experiment (CAVE)" [46]. We used monthly averaged data with the lowest temporal resolution. The data provided by CAVE averages $1 \mathrm{~min}$ data into $15 \mathrm{~min}$ data; if there are any gaps, then the gaps are filled via interpolation of the $15 \mathrm{~min}$ data. Hourly, daily, and monthly averaging was performed using interpolated data.

The sources for the ground observation data included the following institutions: the Baseline Surface Radiation Network (BSRN), the Swiss Federal Institute, and the United States Department of Energy Atmospheric Research Measurement (ARM) Program. The six ground data location sites (Figure 1) are as follows: ALE, NYA, TIK, BAR, SMT, and NSA. BSRN provided Alert (ALE), Ny Alesund (NYA), Tiksi (TIK), and Barrow (BAR) data. BSRN, initiated in 1992 through the World Climate Research Programme (WCRP), was designed in 2004 to be a global baseline network of surface radiant energy for the Global Climate Observing System (GCOS). It also contributes to the Global Atmosphere Watch program by providing high-quality data from a variety of climatic zones [47-49]. The Swiss Federal Institute of Technology (ETH) sources ETH/Greenland Summit (SMT) data that belongs to the Integrated Characterization of Energy, Clouds, Atmospheric State, and Precipitation at Summit (ICECAPS) project. ETH maintains the data, consisting of broadband radiative flux measurements at Summit Station [50]. North Slope of Alaska (NSA) data on the physical conditions of the Arctic atmosphere are provided by ARM [51]. Table 2 shows a detailed information on the six ground observation sites.

2.2. Method. This research is divided into two parts: (1) validation of the net radiation products using ground observation data and (2) an intercomparison among the products in an attempt to better understand the characteristics of the data (Figure 2). In the research flow chart, the yellow square box is the validation part and the green box is the intercomparison part. Validation is performed through three analyses after collocation with measured data using spatial data. And it analyzes the characteristics of the differences of each data through five intercomparison analyses.

In the validation part of the study, the four net radiation products were compared using ground observation data. Collocation of the spatial data was carried out using a minimum distance method. The method of the minimum distance found the nearest location using the great-circle distance. The distance between each point is obtained through

$$
\begin{gathered}
d=r \Delta \sigma \\
\Delta \sigma=2 \arcsin \left(\sqrt{\sin \left(\frac{\Delta l a t}{2}\right)+\cos l a t_{1} \cos l a t_{2}\left(\frac{\Delta l o n}{2}\right)}\right) .
\end{gathered}
$$


TABLE 2: Overview of the ground observation data.

\begin{tabular}{lccc}
\hline Site & Location (latitude, longitude) & Observation site data source & Data periods \\
\hline TIK & $71.59,128.92$, Elev: $48 \mathrm{~m}$ & WCRP/GEWEX Baseline Surface Radiation Network (BSRN) & $2011.04-2016.12$ \\
SMT & $72.60,321.58$, Elev: $3216 \mathrm{~m}$ & Swiss Federal Institute, ETH broadband radiometer measurements & $2011.01-2014.06$ \\
NYA & $78.93,11.93$, Elev: $11 \mathrm{~m}$ & WCRP/GEWEX Baseline Surface Radiation Network (BSRN) & $2000.03-2018.03$ \\
NSA & $71.32,203.39$, Elev: $8 \mathrm{~m}$ & DOE Atmospheric Research Measurement (ARM) Program & $2000.03-2018.03$ \\
ALE & $82.45,297.49$, Elev: $200 \mathrm{~m}$ & WCRP/GEWEX Baseline Surface Radiation Network (BSRN) & $2004.07-2014.03$ \\
BAR & $71.32,203.39$, Elev: $8 \mathrm{~m}$ & WCRP/GEWEX Baseline Surface Radiation Network (BSRN) & $2000.03-2017.08$ \\
\hline
\end{tabular}

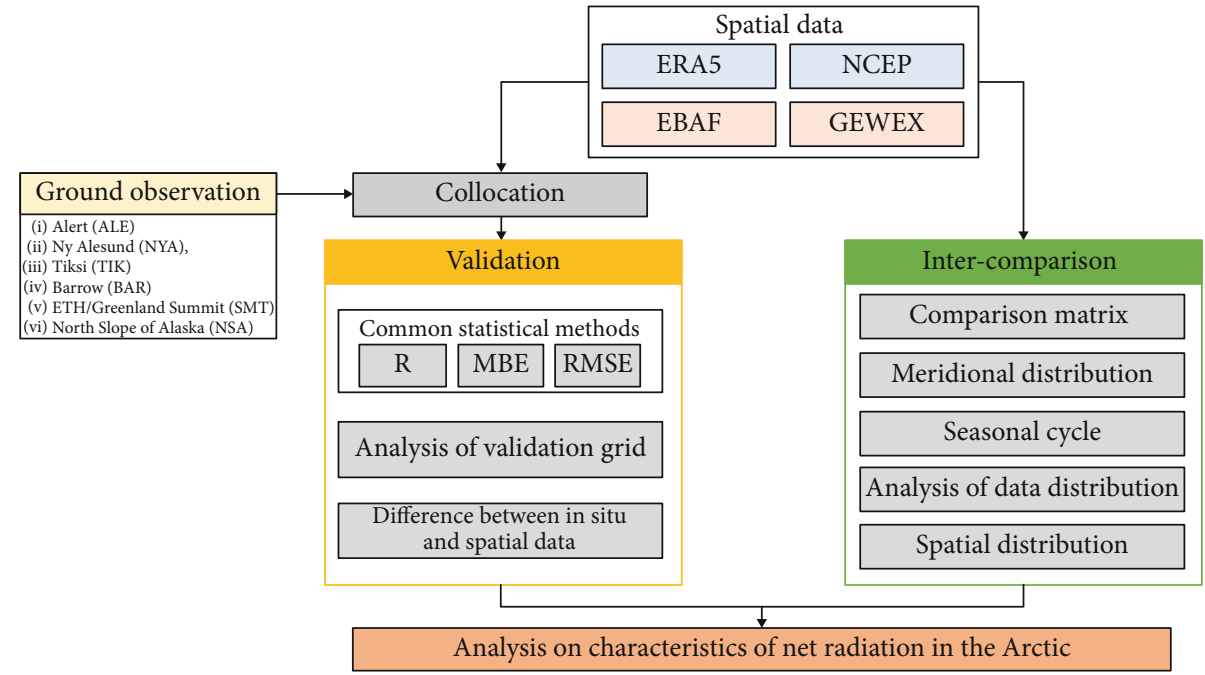

Figure 2: Flow chart to analyze the characteristics of the Arctic net radiation.

$d$ refers the distance between ground observation data and spatial product. Find and compare the point where this distance is the minimum. $r$ refers to the radius of sphere, $\Delta$ $\sigma$ refers to the central angle, and lat ${ }_{1}$ and lat ${ }_{2}$ refer to the latitude at ground observation and net radiation products to be compared. The absolute difference between longitude and latitude between two points is denoted by $\Delta$ lat and $\Delta \mathrm{lon}$.

Three common statistical methods were used for the validation $[11,52]$ : the correlation coefficient $(R)$, root mean square error/difference (RMSE/RMSD), and mean bias error (MBE). The $R$-value here indicates the correlation between observation data and spatial data of the net radiation products: closer to $1(-1)$ indicates a strong positive (negative) relationship with ground observation or comparison data. $R$ $>0$ indicates that there is a positive correlation, $R<0$ indicates a negative correlation, and $R=0$ indicates that the data being compared are uncorrelated. RMSE is associated with the weight of the maximum error [53]; this is sometimes referred to as RMSD between values being modeled. MBE indicates systematic differences [52]. Positive (negative) MBE represents an overestimation (underestimation). The statistical characteristics of ground observation data were analyzed. In addition, the validation grid of net radiation data was analyzed using a box plot owing to the different spatial resolutions. The plot represents the information as a univariate distribution with the advantages of an approximate range and the ability to accommodate greater variability.
The second part of the study involved an intercomparison of the spatial net radiation products over the Arctic Circle, to analyze the differences among products used in actual research in the area. The study period was designated as March 2000 to December 2007, where all four datasets existed, thus over an approximately 8 -year period. The intercomparison part of the study was further divided into four parts. First, the entire Arctic Circle was compared and analyzed as a large region from $65^{\circ} \mathrm{N}$ poleward. Second, a correlation analysis was conducted among the products. Third, the $R$-value, MBE, and RMSD were calculated. Finally, the results were configured in matrix form to intuitively analyze the correlation relationships among the radiation products for the Arctic Circle region. Individual data points were compared using the average net radiation in the Arctic Circle.

In the second part, the meridional distribution and seasonal cycle parts were analyzed separately. For analysis of the meridional distribution, we calculated the zonal mean at $2^{\circ}$ intervals, as this corresponds to the spatial resolution of NCEP (with a resolution greater than $1^{\circ}$ ). The distribution of net radiation for each datum was analyzed by averaging every $2^{\circ}$ from $60^{\circ} \mathrm{N}$ to $90^{\circ} \mathrm{N}$. We also examined the seasonal cycle. In the third part, the distributions of actual pixel values were analyzed using histogram data and scatter density plots of the Arctic Circle region. Histogram analysis was conducted to confirm the data distribution over the comparison period by analyzing the maximum and minimum peak 


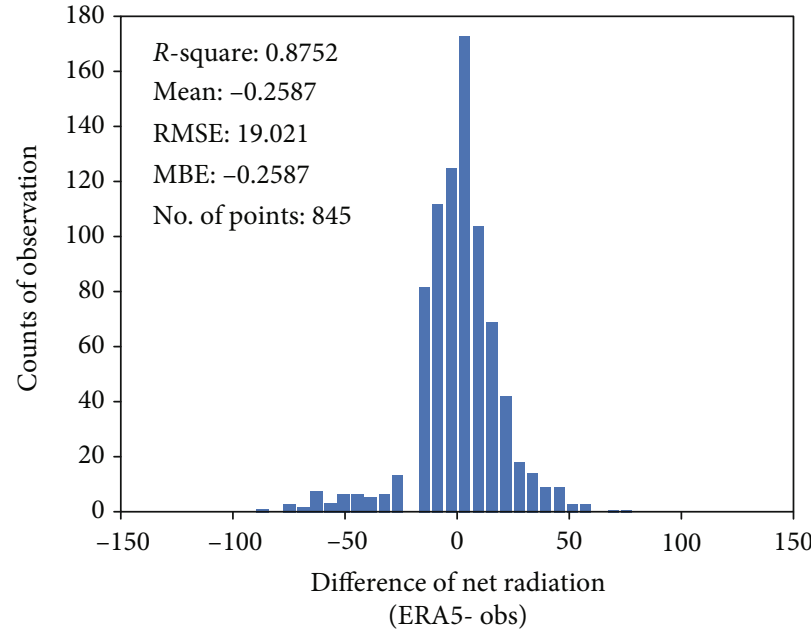

(a)

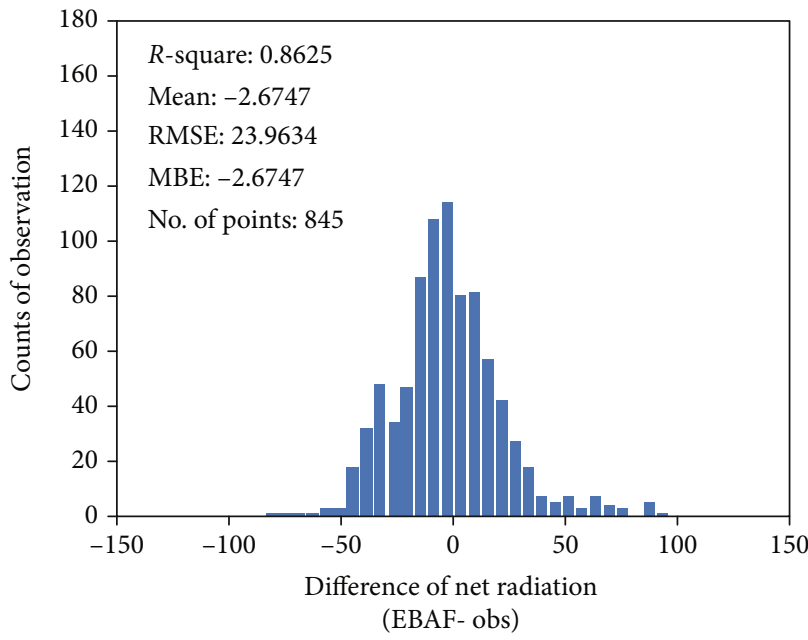

(c)

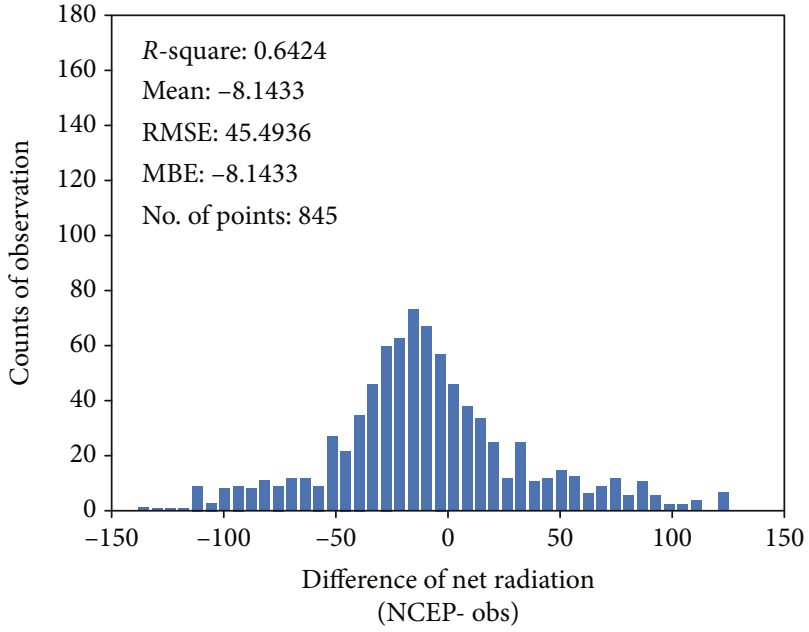

(b)

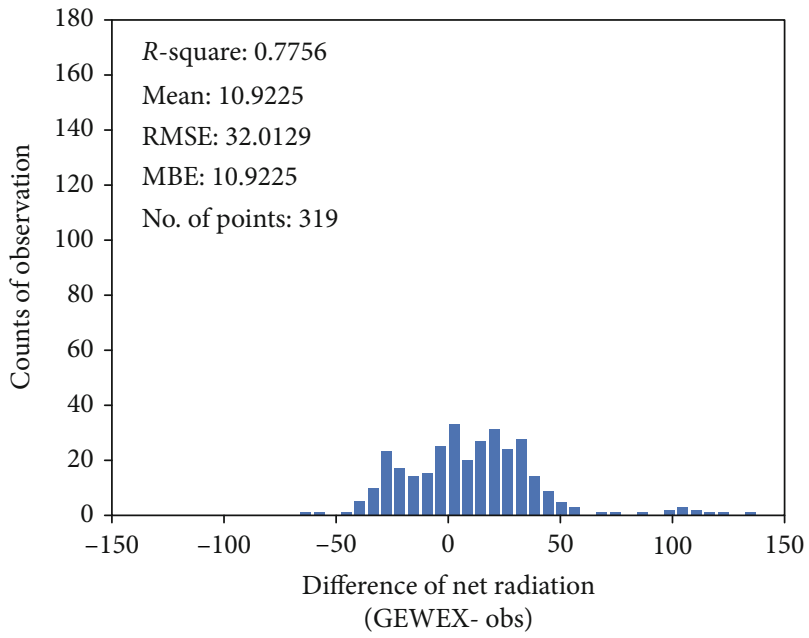

(d)

Figure 3: Histograms showing the difference between ground observation data and net radiation data from (a) the fifth generation of European Centre for Medium-Range Weather Forecasts atmospheric reanalysis of the global climate (ERA5), (b) National Centers for Environmental Prediction (NCEP), (c) Earth's Radiant Energy System Energy Balanced and Filled (EBAF), and (d) Global Energy and Water Exchanges (GEWEX) products.

distributions and the range of values. Scatter density plot analysis was performed with high accuracy, in connection with the validation part. Finally, we analyzed the differences in spatial distributions in matrix form to identify the characteristics of the products with respect to the Arctic region.

\section{Results and Discussion}

\subsection{Validation with Ground Observation Data}

3.1.1. Overview of the Validation. Figure 3 shows histogram plots of the differences between ground observation data and individual net radiation products. ERA5 data were more accurate than the other products, with a coefficient of determination $\left(R^{2}\right)$ of 0.88 , an RMSE of $19.02 \mathrm{~W} / \mathrm{m}^{2}$, and a low MBE of $-0.26 \mathrm{~W} / \mathrm{m}^{2}$. Compared to the other products, the difference was concentrated at 0 , indicating a low variance.
In contrast, NCEP was observed to have the lowest accuracy among the products, with an $R^{2}$ value of 0.64 , an RMSE of $45.49 \mathrm{~W} / \mathrm{m}^{2}$, and an MBE of $-8.14 \mathrm{~W} / \mathrm{m}^{2}$; in this case, the data appeared to be widely scattered, as evidenced by the high $\mathrm{MBE}$ and variance (standard deviation: $44.76 \mathrm{~W} / \mathrm{m}^{2}$ ). EBAF showed an $R^{2}$ of 0.86 , an RMSE of $23.96 \mathrm{~W} / \mathrm{m}^{2}$, and an MBE of $-2.37 \mathrm{~W} / \mathrm{m}^{2}$, with a standard deviation of $23.81 \mathrm{~W} / \mathrm{m}^{2}$ as the second most accurate product. GEWEX was only available until 2007. Thus, the number of samples was small compared to the other data. Only the mean of the difference was observed in GEWEX, with an $R^{2}$ value of 0.78 , an RMSE of $32.01 \mathrm{~W} / \mathrm{m}^{2}$, an MBE of $10.92 \mathrm{~W} / \mathrm{m}^{2}$, and a standard deviation of $30.09 \mathrm{~W} / \mathrm{m}^{2}$. Overall, the most accurate model was ERA5, followed by EBAF, GEWEX, and NCEP.

The validation results for ground observation data are shown as Table 3. TIK and SMT locations have data going 
TABLE 3: Validation of the four net radiation products by ground observation site (six sites total).

\begin{tabular}{|c|c|c|c|c|c|}
\hline Site & & ERA5 & NCEP & EBAF & GEWEX \\
\hline \multirow{3}{*}{ TIK } & $R$ & 0.96 & 0.86 & 0.97 & - \\
\hline & $\operatorname{RMSE}\left(\mathrm{W} / \mathrm{m}^{2}\right)$ & 14.92 & 36.77 & 22.22 & - \\
\hline & $\operatorname{MBE}\left(\mathrm{W} / \mathrm{m}^{2}\right)$ & 5.22 & 5.05 & -4.41 & - \\
\hline \multirow{3}{*}{ SMT } & $R$ & 0.94 & 0.88 & 0.63 & - \\
\hline & $\operatorname{RMSE}\left(\mathrm{W} / \mathrm{m}^{2}\right)$ & 8.45 & 23.25 & 20.78 & - \\
\hline & $\operatorname{MBE}\left(\mathrm{W} / \mathrm{m}^{2}\right)$ & -5.76 & -10.47 & 18.61 & - \\
\hline \multirow{3}{*}{ NYA } & $R$ & 0.94 & 0.91 & 0.93 & 0.91 \\
\hline & $\operatorname{RMSE}\left(\mathrm{W} / \mathrm{m}^{2}\right)$ & 26.95 & 65.62 & 35.99 & 46.64 \\
\hline & $\operatorname{MBE}\left(\mathrm{W} / \mathrm{m}^{2}\right)$ & -18.52 & -4.03 & -7.11 & 12.27 \\
\hline \multirow{3}{*}{ NSA } & $R$ & 0.97 & 0.83 & 0.96 & 0.94 \\
\hline & $\operatorname{RMSE}\left(\mathrm{W} / \mathrm{m}^{2}\right)$ & 14.39 & 37.59 & 16.30 & 22.21 \\
\hline & $\operatorname{MBE}\left(\mathrm{W} / \mathrm{m}^{2}\right)$ & 6.61 & -10.15 & -2.51 & 10.73 \\
\hline \multirow{3}{*}{ ALE } & $R$ & 0.94 & 0.84 & 0.96 & 0.92 \\
\hline & $\operatorname{RMSE}\left(\mathrm{W} / \mathrm{m}^{2}\right)$ & 21.41 & 28.94 & 17.64 & 21.63 \\
\hline & $\operatorname{MBE}\left(\mathrm{W} / \mathrm{m}^{2}\right)$ & 13.79 & -9.34 & 4.79 & 10.09 \\
\hline \multirow{3}{*}{ BAR } & $R$ & 0.97 & 0.81 & 0.96 & 0.93 \\
\hline & $\operatorname{RMSE}\left(\mathrm{W} / \mathrm{m}^{2}\right)$ & 14.52 & 41.29 & 19.1 & 25.07 \\
\hline & $\operatorname{MBE}\left(\mathrm{W} / \mathrm{m}^{2}\right)$ & 2.83 & -13.59 & -6.13 & 10.10 \\
\hline
\end{tabular}

back to 2007, preventing a comparison with GEWEX. EBAF showed a significantly lower correlation at SMT than other sites. ERA5 indicated high accuracy with a strong correlation, low RMSE, and an MBE approaching 0.

3.1.2. Analysis of the Net Radiation Distribution. The validation pixel of each data point was analyzed due to the different grid sizes of each product. The statistical distribution of the grid used for validation was confirmed, as shown in Figure 4; observation data are represented by a black box in the figure. Overall, ERA5 showed a denser distribution than NCEP, for which the distribution was scattered considerably. However, the interquartile range (IQR) for the two products was similar. Thus, the values of the net radiation were similarly distributed. In addition, all data exhibited a negative skewness with respect to their distributions, as the mean was higher than the median value. The distribution of data was observed differently depending on the surface conditions. In SMT, which is a homogeneous surface, the IQR of most data was observed to be small. However, in the case of heterogeneous surface condition as NYA, the IQR was determined according to the grid to validation. The NCEP with the lowest spatial resolution was observed to have the largest IQR, and the IQR of ERA5 with the high spatial resolution was observed to be small.

The statistical characteristics of each observation site are as follows. SMT showed an average net radiation of $-12.45 \mathrm{~W} / \mathrm{m}^{2}$ (standard deviation: $11.73(25.72 \%) \mathrm{W} / \mathrm{m}^{2}$ ). This site had a short-duration coverage of just 3 years. SMT is located in the center of Greenland, and it has a homogeneous surface compared with the other sites. The data varia- tion was also smaller at SMT compared with the other sites. BAR showed an average net radiation of $21.58 \mathrm{~W} / \mathrm{m}^{2}$ (standard deviation: $\left.60.72(25.57 \%) \mathrm{W} / \mathrm{m}^{2}\right)$. Therefore, the data variation was larger than in other regions. The other ground observation sites, TIK, NYA, NSA, and ALE, showed average net radiation values of $19.34,5.41,16.16$, and $-1.99, \mathrm{~W} / \mathrm{m}^{2}$, respectively, with standard deviations of $51.58(30.09 \%)$, 48.28 (26.38\%), 56.87 (24.29\%), and $46.53(25.43 \%) \mathrm{W} / \mathrm{m}^{2}$.

\subsection{Intercomparison of Net Radiation Products}

3.2.1. Comparison Matrix of the Arctic Circle. In the intercomparison of four net radiation products, a confusion matrix was used to highlight the differences among data expressed in terms of the $R$-value, RMSD, and MBE (Figure 5). All products showed strong relationships with the other three products, with correlation coefficients exceeding 0.9. The MBE was positive, based on $x$-axis data. GEWEX appeared to overestimate the net radiation compared with the other products. The RMSD varied over a wide range, from 6.16 to $21.19 \mathrm{~W} / \mathrm{m}^{2}$. The lowest RMSD corresponded to a comparison between EBAF and ERA5 but was highest between GEWES and NCEP. In the reanalysis data, the secondary low in the RMSD was $9.60 \mathrm{~W} / \mathrm{m}^{2}$; the difference from the largest to the smallest was in the following order: EBAF/NCEP, GEWEX/EBAF, and GEWEX/ERA5. GEWEX showed the largest difference in comparison with satellitederived data, such as EBAF. Thus, all data showed a high correlation; however, the MBE and RMSD indicated high variation, despite similar patterns in the data. Thus, the differences associated with the variation in data and the range of 


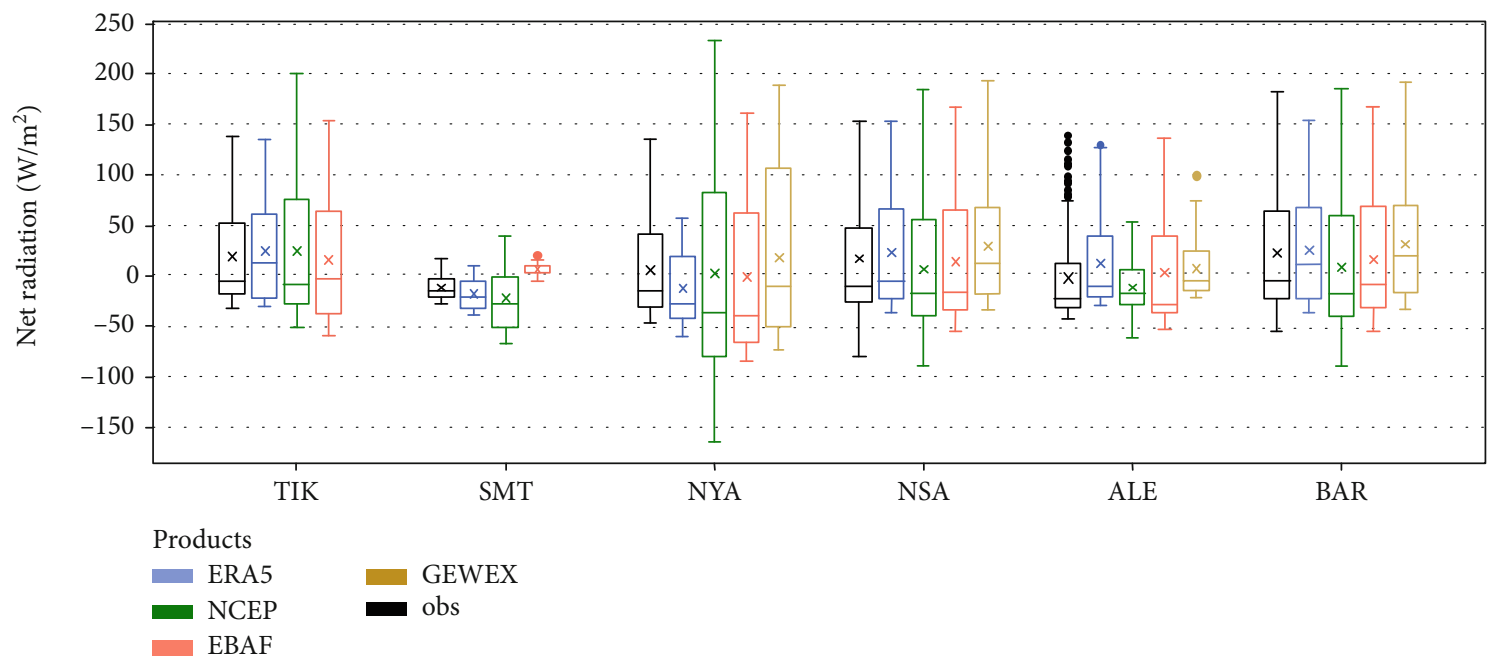

FIGURE 4: Distributions of the validation grid at ground observation sites; the $\mathrm{x}$ marker indicates the average. The reanalysis data of ERA5 and NCEP are indicated by blue and green, respectively, and satellite-based data for EBAF and GEWEX are indicated by red and yellow, respectively, with individual observations shown as a black dot.

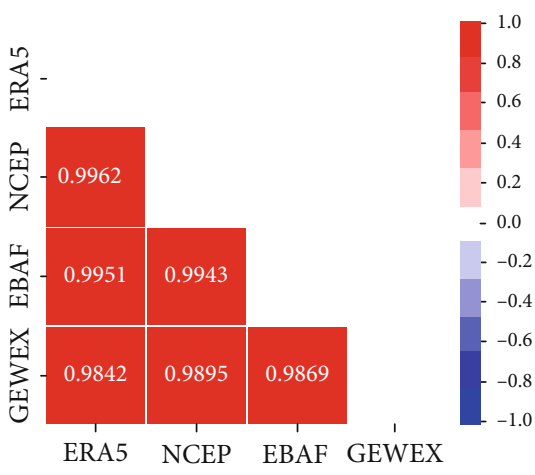

(a)

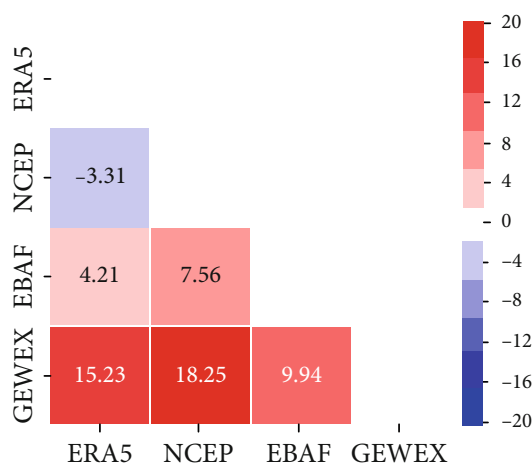

(b)

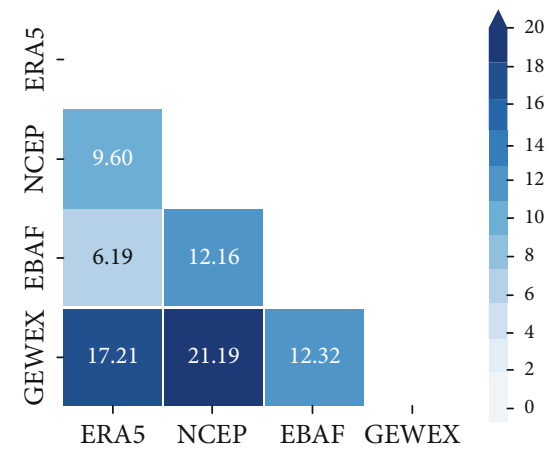

(c)

FIgURE 5: Confusion matrices for the intercomparison of all-grid average values from the four radiation products in the Arctic Circle: (a) correlation coefficients $(R)$, (b) mean bias error (MBE), and (c) root-mean square difference (RMSD).

observing values appeared to strongly affect the agreement among radiation products.

\subsubsection{Comparisons of Meridional Distribution and Seasonal} Cycle. To understand the characteristics of net radiation data for latitude, we analyzed the $2^{\circ}$ zonal mean for each of the four products; this was chosen based on the spatial resolution of NCEP data. In a previous study, the same method was used to analyze meridional characteristics [54]. Figure 6(a) shows the net radiation distribution according to latitude. GEWEX data were $5 \sim 10 \mathrm{~W} / \mathrm{m}^{2}$ higher than other data. Net radiation was highest in the order of GEWEX, EBAF, ERA5, and NCEP. All data showed a decreasing pattern between latitudes $60^{\circ} \mathrm{N}$ and $78^{\circ} \mathrm{N}$. However, above $78^{\circ} \mathrm{N}$, 


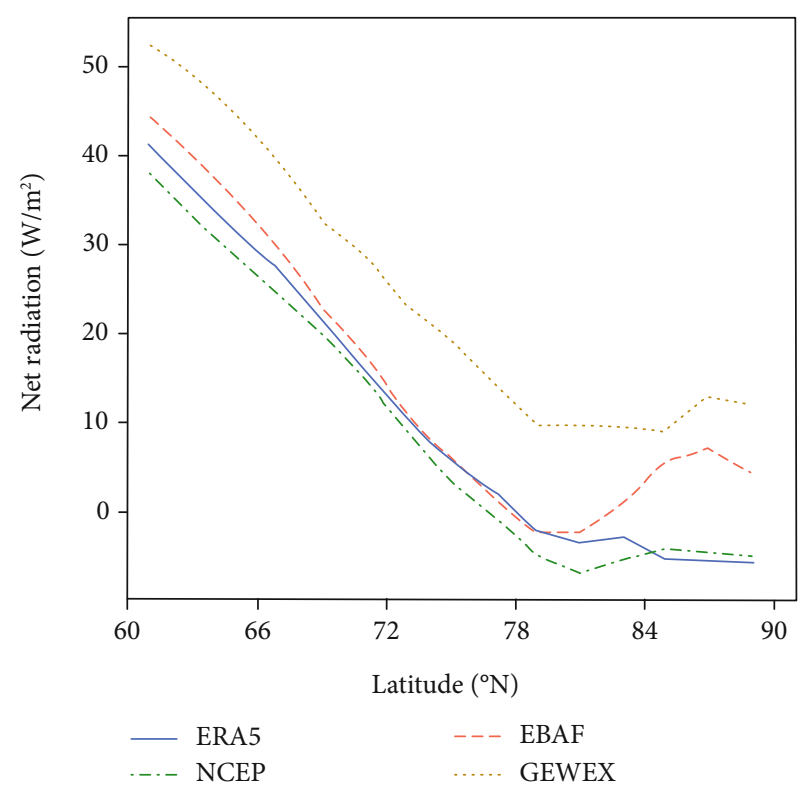

(a)

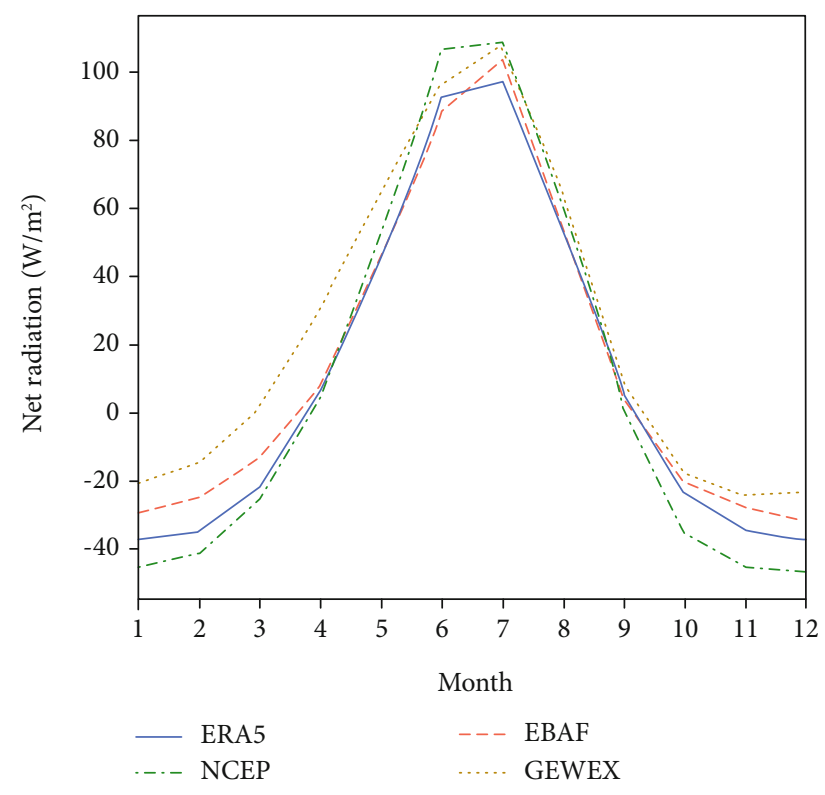

(b)

FIgURE 6: Two-degree zonal means and seasonal cycle in the Arctic: (a) distribution of the $2^{\circ}$ zonal mean by latitude; (b) seasonal cycle of net radiation averaged in the Arctic Circle. In both graphs $(\mathrm{a}, \mathrm{b})$, the reanalysis data of ERA5 and NCEP are indicated by blue and green lines, respectively, and satellite-based data as EBAF and GEWEX are indicated by red and yellow lines, respectively.

differences among the distributions emerged. ERA5 showed a poleward decrease in net radiation. In NCEP net radiation data, a decreasing pattern was observed initially closer to $60^{\circ}$; however, an increasing pattern developed at latitude $80^{\circ} \mathrm{N}$. The net radiation distribution of EBAF data by latitude was divided into three ranges. In first range from $60^{\circ} \mathrm{N}$ to $78^{\circ} \mathrm{N}$, the net radiation of EBAF showed a decreasing trend, similar to ERA5 and NCEP. However, the EBAF distribution rose from latitude $78^{\circ} \mathrm{N}$ to $86^{\circ} \mathrm{N}$. Above $86^{\circ} \mathrm{N}$, the EBAF net radiation pattern again showed a reduction. Similarly, the GEWEX net radiation exhibited a decreasing pattern up to latitude $78^{\circ} \mathrm{N}$. From $78^{\circ} \mathrm{N}$ to $84^{\circ} \mathrm{N}$, the net radiation for GEWEX remained relatively the same, regardless of latitude.

Figure 6(b) shows the seasonal cycle distribution. Except for summer, GEWEX indicate overestimation compared to for net radiation products, which was consistent with MBE in the confusion matrix and the $2^{\circ}$ zonal mean by latitude. In all data, the maximum value of net radiation corresponded to summer in July, and the minimum value coincided with winter in December. This pattern is similar to the variation in temperature and the number of hours of daylight [55]; thus, this characteristic is caused by the polar night, because incoming solar radiation is weak or nonexistent in the autumn and winter seasons. Thus, the seasonal variation of the net radiation can be divided into two periods: from April to September and from October to March. The period from April to September includes the melting season and summer. During this time, differences in the data were reduced. Notably, EBAF and ERA5 distributions were similar. The second period from October to March included the freezing season and winter. During this period, the differences among the radiation products increased and the net radiation recorded increased in the order from the largest to the smallest of GEWEX, EBAF, ERA5, and NCEP.

3.2.3. Comparison with Distribution of Data per Grid. The confusion matrix analysis was performed by averaging the Arctic Circle region as one region. The Arctic has a highly seasonal cycle, as indicated in all four radiation products. However, using the $2^{\circ}$ zonal mean, we confirmed differences in latitude patterns within the Arctic Circle. Figure 7 shows a histogram of the four net radiation products. ERA5 showed an average of $4.74 \mathrm{~W} / \mathrm{m}^{2}$ and a standard deviation of $51.39 \mathrm{~W} / \mathrm{m}^{2}$ for a total of $13,392,000$ samples. In this case, the standard deviation accounted for $14.68 \%$ of the total value. NCEP had an average of $1.77 \mathrm{~W} / \mathrm{m}^{2}$ and a standard deviation of $58.58 \mathrm{~W} / \mathrm{m}^{2}$ for a total of 214,272 samples; here, the standard deviation accounted for $14.44 \%$ of the total value. EBAF produced an average of $10.07 \mathrm{~W} / \mathrm{m}^{2}$ and a standard deviation of $50.51 \mathrm{~W} / \mathrm{m}^{2}$ for a total of 837,000 samples, with the standard deviation accounting for $14.68 \%$ of the total value. ERA5 produced an average of $20.01 \mathrm{~W} / \mathrm{m}^{2}$ and a standard deviation of $51.08 \mathrm{~W} / \mathrm{m}^{2}$ for a total of 837,000 samples; in this case, the standard deviation accounted for $15.04 \%$ of the total value. The NCEP product had the widest data distribution, whereas GEWEX was more concentrated. Satellite data also indicated a higher mean compared to that of reanalysis data.

Figure 8 shows the monthly density scatter of net radiation for NCEP, EBAF, and GEWEX based on ERA5; here, the $x$-axis represents ERA5 and the $y$-axis represents comparative data in the figure. Most of the net radiation values were distributed over a low range $\left(<30 \mathrm{~W} / \mathrm{m}^{2}\right)$. All data had a $R^{2}$ above 0.9 , indicating a strong relationship with ERA5. 


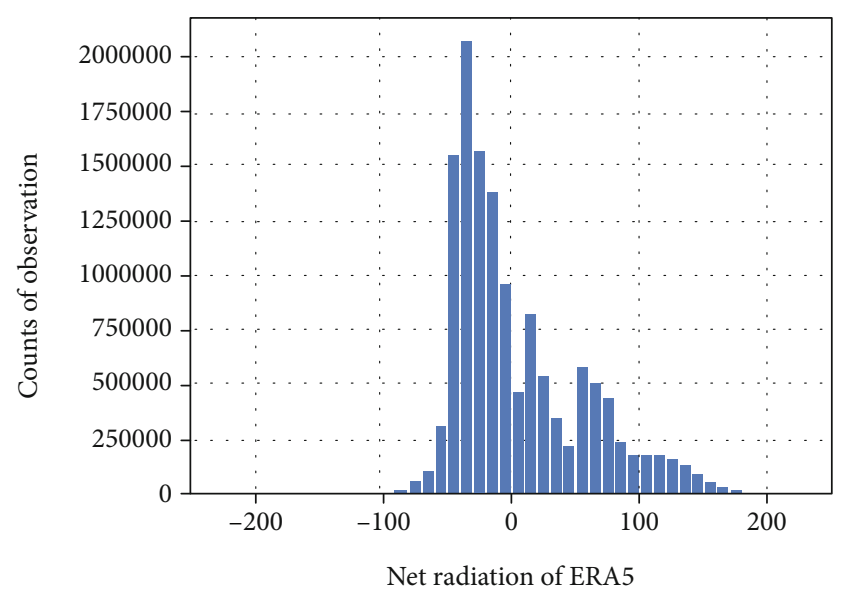

(a)

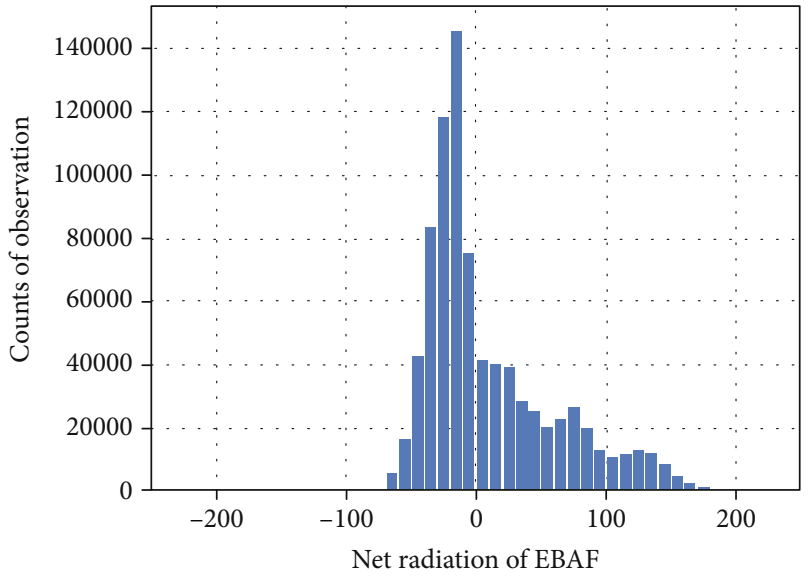

(c)

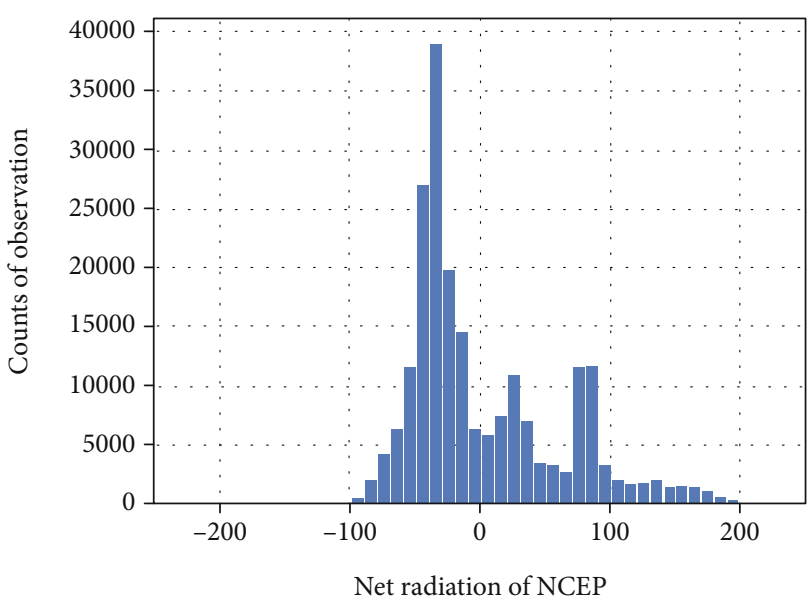

(b)

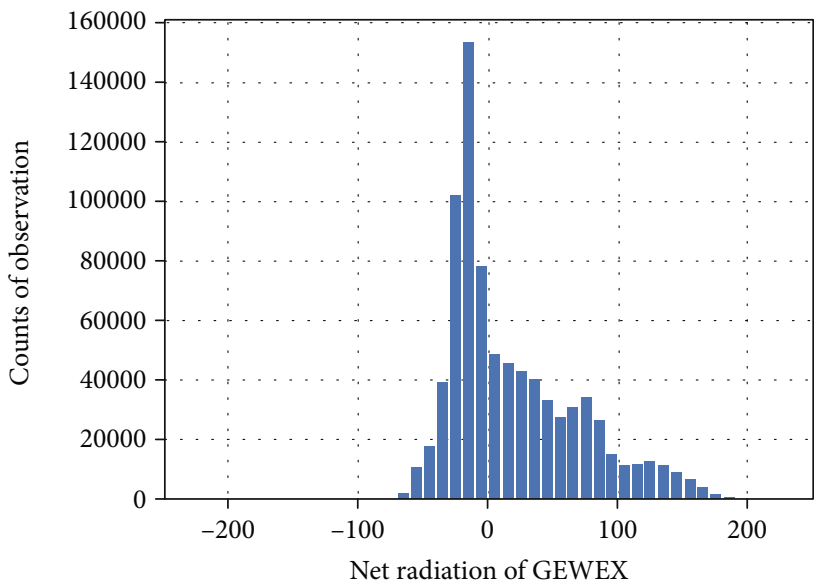

(d)

FIgure 7: Histogram of net radiation in the Arctic Circle from March 2000 to December 2007: (a) ERA5, (b) NCEP, (c) EBAF, and (d) GEWEX.
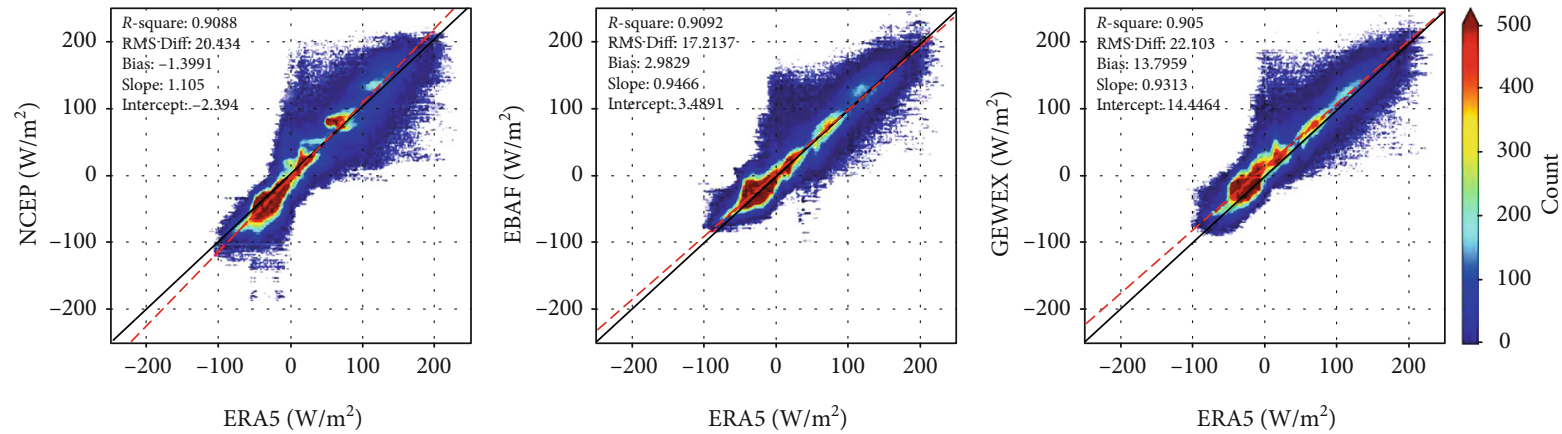

FIGURE 8: Density scatter between ERA5 and the other net radiation products. The $x$-axis represents ERA5 data, and the $y$-axis corresponds to (a) NCEP, (b) EBAF, and (c) GEWEX data.

With respect to ERA5, the differences among NCEP, EBAF, and GEWEX data were $-1.40 \pm 20.43,2.98 \pm 17.21$, and $13.80 \pm 22.10 \mathrm{~W} / \mathrm{m}^{2}$, respectively. NCEP data were lower than the $1: 1$ line in range, where values below zero were distributed. In addition, the data indicated a more widespread distribution of net radiation. EBAF data were similar to ERA5 data, as indicated by the regression line fit. The regres- sion line of GEWEX was generally higher than the 1:1 line; thus, GEWEX data tended to show higher values than ERA5. The density scatter distribution of GEWEX-ERA5 was more similar to EBAF data than NCEP.

3.2.4. Differences in Spatial Distribution. We analyzed the spatial differences in net radiation between NCEP, EBAF, 


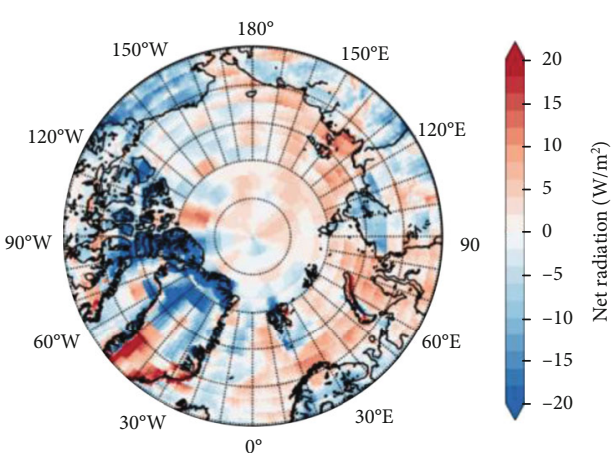

(a)

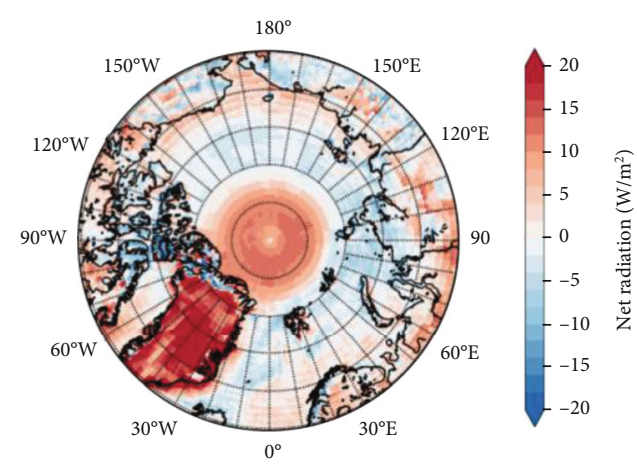

(b)

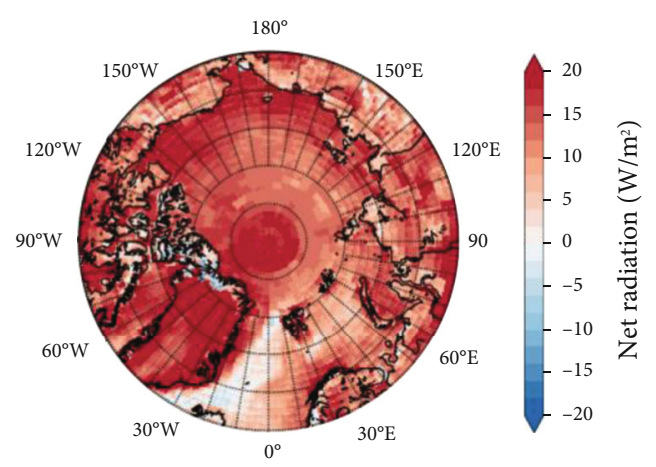

(c)

FIgURE 9: Distribution of spatial differences in net radiation based on ERA5 from March 2000 to December 2007. The red shading indicates an overestimation of the compared net radiation product, and blue shading indicates an underestimation. (a) NCEP-ERA5, (b) EBAF-ERA5, and (c) GEWEX-ERA5.

and GEWEX in the Arctic Circle, based on ERA5 data, as shown in Figure 9; the red shading indicates an overestimation of the corresponding data, and the blue shading indicates underestimation. In the case of NCEP, a mixture of overestimation and underestimation is shown in the figure. The net radiation differences were smaller over oceans than continents, with overestimation in the east and underestimation in the west. Regarding land areas, Canada and North Greenland showed a strong underestimation in net radiation, whereas South Greenland was overestimated. In the case of EBAF, less of a difference was observed compared with the other two datasets. Thus, substantial discrepancies were evident among the radiation products in Greenland. Also, the central Arctic area exhibited an overestimation of the net radiation, which was consistent with the $2^{\circ}$ zonal mean by latitude. EBAF data indicated an increase in net radiation from $78^{\circ} \mathrm{N}$ to $86^{\circ} \mathrm{N}$, whereas in the ocean adjoining the Central Arctic, a small underestimation was evident. In the case of GEWEX, the entire area was overestimated, with the exception of a few areas. The north coastline of Greenland and East Greenland Sea showed an underestimation in net radiation. These areas were underestimated in all comparisons; thus, ERA5 always estimated a high net radiation value in the area. These regional characteristics should be noted when using ERA5 data. Different regional characteristics were observed in GEWEX and EBAF. The two products are the same satellite-based data, but there is a difference in the radiative transfer scheme between the two products. The dif- ference in the net radiated energy of the two data may occur primarily due to the difference in the method of calculating the radiation data. There are also differences in the cloud data used. CERES EBAF uses MODIS data and SAR-based CALIPSO/CloudSat data, and GEWEX uses ISCCP DX data. In Figures 9(b) and 9(c), both EBAF and GEWEX data are overestimated compared to ERA5 data in the area above about $80^{\circ} \mathrm{N}$, which is the area where CALIPSO/CloudSat observations are missing. The two satellite-based data show the same characteristics in the region where CALIPSO/CloudSat data is excluded. Therefore, differences in satellite-based net radiation may occur due to differences in input cloud data.

\section{Summary and Conclusions}

In this study, we evaluated the surface net radiation from reanalysis (ERA5 and NCEP) and satellite-based (EBAF and GEWEX) products in the Arctic region. The maximum validation period was from March 2000 to March 2018, and the product comparison period was from March 2000 to December 2007, during which all data overlapped. The overall results for the validation process indicated ERA5 as having the highest accuracy of the four products. The quantitative accuracies of the four products were as follows: ERA5, $0.26 \pm 19.02$; EBAF, $-2.37 \pm 23.96$; GEWEX, $10.92 \pm 32.01$; and NCEP, $-8.14 \pm 45.49 \mathrm{~W} / \mathrm{m}^{2}$. ERA5 and EBAF showed similar accuracies with respect to CERES EBAF (RMSE: 20.93, MBE: 2.40), with higher uncertainty at higher latitudes 
[11]. The difference in accuracy may be due to spatial resolution. ERA5, the smallest valid grid, showed a distribution of values similar to the observation data. In the case of NYA, this particular observation site is located on an island (Svalbard, a Norwegian island); here, the grid size was larger, resulting in a larger IQR. The reason for the lower accuracy in EBAF than ERA5 can be attributed to the low accuracy of the CERES inversion for the snow surface and the uncertainty in the matchup near the coastal line due to the low spatial resolution [56].

The reason for focusing on these differences is that the Arctic is covered in ice; thus, the ice albedo effect is important. In particular, net radiation is connected to the icealbedo feedback mechanism, making this feedback a key parameter of climate change in the Arctic $[6,57]$. When analyzing climate change, differences in model accuracy and patterns of change are due to differences in the net radiation. Thus, it is essential to monitor and improve the assessments of surface energy budgets to better understand and predict climate change [28]. Continuous research in this area is essential for a process-level connection between the model and observations [58].

The purpose of this study was to attempt to better understand the accuracy of net radiation products in high-latitude areas and the differences among products. This helps when selecting a product for climate change modeling. Based on the results from this study, it is possible to analyze longterm energy changes in the Arctic by selecting the optimized net radiation energy.

The validation results were limited to ground observation sites covered with ice. Since the Arctic Circle is mainly composed of oceans, validation in sea ice is an essential part. Therefore, it is necessary to add the net radiation validation of sea ice using drift data in the future. In this study, differences occurred between net radiated products and the characteristics of the differences were analyzed. However, it was not possible to find out what factors caused such differences. Therefore, future research will need to consider the factors responsible for creating differences in the net radiation products. There are many different things that cause differences in net radiation. It is necessary to study what factors cause the difference in net radiation from the results of this study.

The radiative energy component is expected to play a key role in projecting accurate representations and climate change trends for the Arctic region. Changes in net radiation can help predict variables that cause physical processes in the Arctic such as Arctic sea ice. Based on the results of this study, it can be extended and utilized in long-term energy change observation, sea ice prediction model, and climate change modeling.

It is necessary to analyze which data is most appropriate for analyzing climate change and how the difference between the radiative products has an impact on climate change analysis. A radiative flux such as net radiation can be used as a key parameter to determine the energy balance of the Arctic. These results will enable accurate observation and prediction of Arctic climate and help to identify the causes of recent abnormal climates in connection with the Arctic midlatitude region.

\section{Data Availability}

The data used to support the findings of this study are included within the article.

\section{Conflicts of Interest}

The authors declare that there is no conflict of interest regarding the publication of this paper.

\section{Acknowledgments}

This research was funded by the Korea Polar Research Institute (KOPRI), grant number PE20080. ARM data is made available through the U.S. Department of Energy as part of the Atmospheric Radiation Measurement Program.

\section{References}

[1] M. C. Serreze, A. P. Barrett, A. G. Slater, M. Steele, J. Zhang, and K. E. Trenberth, "The large-scale energy budget of the Arctic," Journal of Geophysical Research: Atmospheres, vol. 112, no. D11, 2007.

[2] IPCC, Climate Change 2013: The Physical Science Basis. Contribution of Working Group I to the Fifth Assessment Report of the Intergovernmental Panel on Climate Change, Cambridge University Press, Cambridge, 2013.

[3] Y. Huang, X. Dong, B. Xi, E. K. Dolinar, R. E. Stanfield, and S. Qiu, "Quantifying the uncertainties of reanalyzed Arctic cloud and radiation properties using satellite surface observations," Journal of Climate, vol. 30, no. 19, pp. 8007-8029, 2017.

[4] S. C. Tsay, K. Stamnes, and K. Jayaweera, "Radiative energy budget in the cloudy and hazy Arctic," Journal of the Atmospheric Sciences, vol. 46, no. 7, pp. 1002-1018, 1989.

[5] J. Cohen and D. Rind, "The effect of snow cover on the climate," Journal of Climate, vol. 4, no. 7, pp. 689-706, 1991.

[6] M. Seo, H.-C. Kim, M. Huh et al., "Long-term variability of surface albedo and its correlation with climatic variables over Antarctica," Remote Sensing, vol. 8, no. 12, 2016.

[7] K. S. Lee, D. Jin, J. M. Yeom et al., "New approach for snow cover detection through spectral pattern recognition with MODIS data," Journal of Sensors, vol. 2017, Article ID 4820905, 15 pages, 2017.

[8] S. Liang, K. Wang, X. Zhang, and M. Wild, "Review on estimation of land surface radiation and energy budgets from ground measurement, remote sensing and model simulations," IEEE Journal of Selected Topics in Applied Earth Observations and Remote Sensing, vol. 3, no. 3, pp. 225-240, 2010.

[9] V. C. P. J. Ramanathan, P. J. Crutzen, J. T. Kiehl, and D. Rosenfeld, "Aerosols, climate, and the hydrological cycle," Science, vol. 294, no. 5549, pp. 2119-2124, 2001.

[10] M. Wild, D. Folini, C. Schär, N. Loeb, E. G. Dutton, and G. König-Langlo, "The global energy balance from a surface perspective," Climate Dynamics, vol. 40, no. 11-12, pp. $3107-$ 3134, 2013.

[11] A. Jia, S. Liang, B. Jiang, X. Zhang, and G. Wang, "Comprehensive assessment of global surface net radiation products and uncertainty analysis," Journal of Geophysical Research: Atmospheres, vol. 123, no. 4, pp. 1970-1989, 2018.

[12] J. M. Ramírez-Cuesta, D. Vanella, S. Consoli, A. Motisi, and M. Minacapilli, “A satellite stand-alone procedure for deriving 
net radiation by using SEVIRI and MODIS products," International Journal of Applied Earth Observation and Geoinformation, vol. 73, pp. 786-799, 2018.

[13] B. A. Wielicki, B. R. Barkstrom, B. A. Baum et al., "Clouds and the Earth's Radiant Energy System (CERES): algorithm overview," IEEE Transactions on Geoscience and Remote Sensing, vol. 36, no. 4, pp. 1127-1141, 1998.

[14] S. J. Cox, AS\&M, Hampton, VA, P. W. Stackhouse et al., "The NASA/GEWEX surface radiation budget project: overview and analysis," in 12th Conference on Atmospheric Radiation, Madison, Wis, 2006, July.

[15] G. L. Stephens, D. G. Vane, S. Tanelli et al., "CloudSat mission: performance and early science after the first year of operation," Journal of Geophysical Research: Atmospheres, vol. 113, no. D8, 2008.

[16] K. G. Karlsson, K. Anttila, J. Trentmann et al., "CLARA-A2: the second edition of the CM SAF cloud and radiation data record from 34 years of global AVHRR data," Atmospheric Chemistry and Physics, vol. 17, no. 9, pp. 5809-5828, 2017.

[17] D. P. Dee, S. M. Uppala, A. J. Simmons et al., "The ERAInterim reanalysis: configuration and performance of the data assimilation system," Quarterly Journal of the Royal Meteorological Society, vol. 137, no. 656, pp. 553-597, 2011.

[18] F. Johannsen, S. Ermida, J. P. A. Martins, Trigo, Nogueira, and Dutra, "Cold bias of ERA5 summertime daily maximum land surface temperature over Iberian Peninsula," Remote Sensing, vol. 11, no. 21, 2019.

[19] E. Kalnay, M. Kanamitsu, R. Kistler et al., "The NCEP/NCAR 40-year reanalysis project," Bulletin of the American Meteorological Society, vol. 77, no. 3, pp. 437-471, 1996.

[20] M. M. Rienecker, M. J. Suarez, R. Gelaro et al., "MERRA: NASA's Modern-Era Retrospective Analysis for Research and Applications," Journal of Climate, vol. 24, no. 14, pp. 3624-3648, 2011.

[21] M. G. Bosilovich, S. Akella, L. Coy et al., "MERRA-2: initial evaluation of the climate," Technical Report Series on Global Modeling and Data Assimilation, NASA Tech. Memo. NASA/TM-2015-104606, 2015, (https://gmao.gsfc.nasa.gov/ pubs/docs/Bosilovich803.pdf.).

[22] S. Kobayashi, Y. Ota, Y. Harada et al., "The JRA-55 reanalysis: general specifications and basic characteristics," Journal of the Meteorological Society of Japan. Ser. II, vol. 93, no. 1, pp. 5-48, 2015.

[23] J. Maslanik, J. C. Key, W. Fowler, T. Nguyen, and X. Wang, "Spatial and temporal variability of satellite-derived cloud and surface characteristics during FIRE-ACE," Journal of Geophysical Research: Atmospheres, vol. 106, no. D14, pp. 1523315249, 2001.

[24] M. Chiacchio, J. Francis, and P. Stackhouse Jr., "Evaluation of methods to estimate the surface downwelling longwave flux during Arctic winter," Journal of Applied Meteorology, vol. 41, no. 3, pp. 306-318, 2002.

[25] J. Liu, J. A. Curry, W. B. Rossow, J. R. Key, and X. Wang, "Comparison of surface radiative flux data sets over the Arctic Ocean," Journal of Geophysical Research: Oceans, vol. 110, no. C2, 2005.

[26] J. E. Kay and T. L'Ecuyer, "Observational constraints on Arctic Ocean clouds and radiative fluxes during the early 21st century," Journal of Geophysical Research: Atmospheres, vol. 118, no. 13, pp. 7219-7236, 2013.

[27] X. Dong, B. Xi, S. Qiu, P. Minnis, S. Sun-Mack, and F. Rose, “A radiation closure study of Arctic stratus cloud microphysical properties using the collocated satellite-surface data and FuLiou radiative transfer model," Journal of Geophysical Research: Atmospheres, vol. 121, no. 17, pp. 10,175-10,198, 2016.

[28] M. W. Christensen, A. Behrangi, T. S. L'ecuyer, N. B. Wood, M. D. Lebsock, and G. L. Stephens, "Arctic observation and reanalysis integrated system: a new data product for validation and climate study," Bulletin of the American Meteorological Society, vol. 97, no. 6, pp. 907-916, 2016.

[29] A. Riihelä, J. R. Key, J. F. Meirink, P. Kuipers Munneke, T. Palo, and K. G. Karlsson, "An intercomparison and validation of satellite-based surface radiative energy flux estimates over the Arctic," Journal of Geophysical Research: Atmospheres, vol. 122, no. 9, pp. 4829-4848, 2017.

[30] M. Seo, E. Lee, K.-s. Lee et al., "Comparative analysis of radiative flux based on satellite over Arctic," Korean Journal of Remote Sensing, vol. 34, no. 6, pp. 1193-1202, 2018.

[31] F. Al Senafi, A. Anis, and V. Menezes, "Surface heat fluxes over the Northern Arabian Gulf and the Northern Red Sea: evaluation of ECMWF-ERA5 and NASA-MERRA2 reanalyses," Atmosphere, vol. 10, no. 9, 2019.

[32] R. Urraca, T. Huld, A. Gracia-Amillo, F. J. Martinez-de-Pison, F. Kaspar, and A. Sanz-Garcia, "Evaluation of global horizontal irradiance estimates from ERA5 and COSMO-REA6 reanalyses using ground and satellite-based data," Solar Energy, vol. 164, pp. 339-354, 2018.

[33] H. Hersbach, B. Bell, P. Berrisford et al., "Global reanalysis: goodbye ERA-Interim, hello ERA5," ECMWF Newsletter, vol. 159, pp. 17-24, 2019.

[34] E. A. Nussbaumer and R. T. Pinker, "Estimating surface longwave radiative fluxes at global scale," Quarterly Journal of the Royal Meteorological Society, vol. 138, no. 665, pp. 10831093, 2012.

[35] A. A. Lacis and J. Hansen, "A parameterization for the absorption of solar radiation in the earth's atmosphere," Journal of the Atmospheric Sciences, vol. 31, no. 1, pp. 118-133, 1974.

[36] M. D. Schwarzkopf and S. B. Fels, "The simplified exchange method revisited: an accurate, rapid method for computation of infrared cooling rates and fluxes," Journal of Geophysical Research, vol. 96, no. D5, pp. 9075-9096, 1991.

[37] S. Bony, Y. Sud, K. M. Lau, J. Susskind, and S. Saha, "Comparison and satellite assessment of NASA/DAO and NCEPNCAR reanalyses over tropical ocean: atmospheric hydrology and radiation," Journal of Climate, vol. 10, no. 6, pp. 14411462, 1997.

[38] CERES, "EBAF-surface Ed4.0 data quality summary (CERES_ EBAF-Surface_Ed4.0_DQS; June 27, 2018),” https://ceres.larc .nasa.gov/documents/DQ_summaries/CERES_EBAFSurface_Ed4.0_DQS.pdf (accessed on 15 May 2020).

[39] S. Kato, F. G. Rose, D. A. Rutan et al., "Surface irradiances of Edition 4.0 Clouds and the Earth's Radiant Energy System (CERES) Energy Balanced and Filled (EBAF) data product," Journal of Climate, vol. 31, no. 11, pp. 4501-4527, 2018.

[40] N. G. Loeb, D. R. Doelling, H. Wang et al., "Clouds and the Earth's Radiant Energy System (CERES) Energy Balanced and Filled (EBAF) top-of-atmosphere (TOA) Edition-4.0 data product," Journal of Climate, vol. 31, no. 2, pp. 895-918, 2018.

[41] A. A. Sörensson and R. C. Ruscica, "Intercomparison and uncertainty assessment of nine evapotranspiration estimates over South America," Water Resources Research, vol. 54, no. 4, pp. 2891-2908, 2018. 
[42] R. T. Pinker and I. Laszlo, "Modeling surface solar irradiance for satellite applications on a global scale," Journal of Applied Meteorology, vol. 31, no. 2, pp. 194-211, 1992.

[43] Q. Fu, K. N. Liou, M. C. Cribb, T. P. Charlock, and A. Grossman, "Multiple scattering parameterization in thermal infrared radiative transfer," Journal of the Atmospheric Sciences, vol. 54, no. 24, pp. 2799-2812, 1997.

[44] T. Zhang, P. W. Stackhouse Jr., S. K. Gupta, S. J. Cox, J. Colleen Mikovitz, and L. M. Hinkelman, "The validation of the GEWEX SRB surface shortwave flux data products using BSRN measurements: a systematic quality control, production and application approach," Journal of Quantitative Spectroscopy and Radiative Transfer, vol. 122, pp. 127-140, 2013.

[45] T. Zhang, P. W. Stackhouse Jr., S. K. Gupta, S. J. Cox, and J. C. Mikovitz, "The validation of the GEWEX SRB surface longwave flux data products using BSRN measurements," Journal of Quantitative Spectroscopy and Radiative Transfer, vol. 150, pp. 134-147, 2015.

[46] D. A. Rutan, F. G. Rose, N. M. Smith, and T. P. Charlock, "Validation data set for CERES surface and atmospheric radiation budget (SARB)," WCRP/GEWEX Newsletter, vol. 11, no. 1, pp. 11-12, 2001.

[47] A. Ohmura, H. Gilgen, H. Hegner et al., "Baseline surface radiation network (BSRN/WCRP): new precision radiometry for climate research," Bulletin of the American Meteorological Society, vol. 79, no. 10, pp. 2115-2136, 1998.

[48] F. Feng and K. Wang, "Merging satellite retrievals and reanalyses to produce global long-term and consistent surface incident solar radiation datasets," Remote Sensing, vol. 10, no. 1, 2018.

[49] W. Zhang, X. Zhang, W. Li et al., "Evaluation of Bayesian multimodel estimation in surface incident shortwave radiation simulation over high latitude areas," Remote Sensing, vol. 11, no. 15, 2019.

[50] N. B. Miller, M. D. Shupe, C. J. Cox, V. P. Walden, D. D. Turner, and K. Steffen, "Cloud radiative forcing at Summit, Greenland," Journal of Climate, vol. 28, no. 15, pp. 62676280, 2015.

[51] X. Dong and G. G. Mace, “Arctic stratus cloud properties and radiative forcing derived from ground-based data collected at Barrow, Alaska," Journal of Climate, vol. 16, no. 3, pp. 445461, 2003.

[52] A. Loew, W. Bell, L. Brocca et al., "Validation practices for satellite-based Earth observation data across communities," Reviews of Geophysics, vol. 55, no. 3, pp. 779-817, 2017.

[53] T. Kato, "Prediction of photovoltaic power generation output and network operation," in Integration of Distributed Energy Resources in Power Systems, pp. 77-108, Academic Press, 2016.

[54] L. Yu, Z. Zhang, S. Zhong et al., "An inter-comparison of six latent and sensible heat flux products over the Southern Ocean," Polar Research, vol. 30, no. 1, 2011.

[55] M. Pidwirny, "Earth-sun relationships and insolation," in Fundamentals of Physical Geography, University of British Columbia, 2nd edition, 2006, Date Viewed. http://www .physicalgeography.net/fundamentals/6i.html (accessed on 15 May 2020).

[56] A. Jia, B. Jiang, S. Liang, X. Zhang, and H. Ma, "Validation and spatiotemporal analysis of CERES surface net radiation product," Remote Sensing, vol. 8, no. 2, 2016.

[57] D. K. Perovich, B. Light, H. Eicken, K. F. Jones, K. Runciman, and S. V. Nghiem, "Increasing solar heating of the Arctic
Ocean and adjacent seas, 1979-2005: Attribution and role in the ice-albedo feedback," Geophysical Research Letters, vol. 34, no. 19, 2007.

[58] J. E. Kay, T. L’Ecuyer, H. Chepfer, N. Loeb, A. Morrison, and G. Cesana, "Recent advances in Arctic cloud and climate research," Current Climate Change Reports, vol. 2, no. 4, pp. 159-169, 2016. 